\title{
The First Algorithm Calculating Cement Injection Volumes in Patients with Spine Metastases Treated with Percutaneous Vertebroplasty
}

This article was published in the following Dove Press journal:

Therapeutics and Clinical Risk Management

\author{
Yunpeng Cui ${ }^{1} *$ \\ Yuanxing $\operatorname{Pan}^{1, *}$ \\ Mingxing Lei ${ }^{2}$ \\ Chuan $\mathrm{Mi}^{\mathrm{l}}$ \\ Bing Wang' \\ Xuedong Shi' \\ 'Department of Orthopedic Surgery, \\ Peking University First Hospital, Beijing, \\ People's Republic of China; ${ }^{2}$ Department \\ of Orthopedic Surgery, Hainan Hospital \\ of Chinese PLA General Hospital, Sanya, \\ People's Republic of China
}

*These authors contributed equally to this work
Correspondence: Xuedong Shi Department of Orthopedic Surgery, The Peking University First Hospital No. 8 Xishiku Street, Xicheng District Beijing 100032 People's Republic of China Tel +86-0 I0-835722II

Email172998774@qq.com
Purpose: This study aims to develop an algorithm to predict cement injection volumes in patients with spine metastases treated with percutaneous vertebroplasty (PVP). Risk factors were also analyzed for intra-spinal canal cement leakages.

Patients and Methods: A retrospective analysis of 584 vertebrae in 251 patients. Patients and vertebrae were divided into three groups based on grades of tumor invasion to the spinal cord. Patients with the complete posterior wall of vertebrae were classified into group A, patients without the complete posterior wall of vertebrae but with normal Dural sac were classified into group B, and patients with deformation of the Dural sac but without neurological symptom were classified into group C. We systematically reviewed demographic data, clinical parameters, radiology features, and cement leakages among the three groups. The multiple linear regressions were used to screen potential risk factors and develop the algorithm to predict injected cement volumes in vertebrae. Significant factors were included in the algorithm. Potential risk factors for intra-spinal canal cement leakage were analyzed using the multiple logistic regressions.

Results: In the study, $17.1 \%(100 / 584)$ of vertebrae occurred cement leakages. Vertebrae in group C $(28.6 \%, 8 / 28)$ had the highest cement leakage rate than patients in group A $(14.4 \%$, $61 / 424)$ and $\mathrm{B}(23.5 \%, 31 / 132)(\mathrm{P}=0.014)$. Vertebrae in group $\mathrm{C}(14.3 \%, 4 / 28)$ were also more prone to intra-spinal canal leakages $(\mathrm{P}=0.003)$. The multiple logistic analysis showed that the Bilsky scale was significantly associated with intra-spinal canal cement leakages $(\mathrm{P}<0.001)$. The multiple linear regression analysis showed that intercept $(\mathrm{P}<0.001)$, treated vertebrae level $(\mathrm{P}<0.001)$, cortical osteolytic destruction in posterior wall $(\mathrm{P}<0.001)$, and Bilsky scale $(\mathrm{P}=0.014)$ were significant and those variables were included in the algorithm. The algorithm was $\mathrm{Y}=3.1627-0.8677 \times$ treated vertebrae level $-0.6182 \times$ cortical osteolytic destruction in the posterior wall $-0.2819 \times$ Bilsky scale.

Conclusion: An algorithm is proposed and can be used to calculate cement injection volumes in spine metastases treated with PVP. This algorithm can facilitate surgical planning and guide cement injections. Bilsky scale is an independent risk factor for intra-spinal canal cement leakages. We do not recommend PVP treated in patients with a Bilsky scale of 2 and 3 mainly due to a high rate of intra-spinal canal cement leakages.

Keywords: spinal metastases, percutaneous vertebroplasty, algorithm, intra-spinal canal leakages, risk factors

\section{Introduction}

The spine is a common metastatic site for advanced malignant tumors and the incidence of spinal metastases has remarkably grown because of the increased survival in cancer patient. ${ }^{1,2}$ Patients with spine metastases were expected to up 
to 15 million globally by the next five years, and the incidence of spine metastases is also expected to increase to no less than $50 \%{ }^{3}$ Patients with spine metastases usually involve intractable back pain that affects the patient's quality of remaining life. ${ }^{4}$ The treatments for this advanced disease warrant interdisciplinary cooperation, including radiotherapies, chemotherapies, and surgical interventions, which were often combined to give a maximum palliative effect with a minimum of morbidity and mortality. ${ }^{5-7}$ Among all treatments, decompressive surgery followed by radiotherapy was regarded as the main standard intervention to spine metastases. ${ }^{8,9}$ However, due to the morbidity of open surgery, the treatment paradigm has shifted towards minimally invasive interventions. $^{2}$

Percutaneous vertebroplasty (PVP) is an important minimally invasive technique in the treatment of patients with spine metastases. It can effectively relieve back pain in $73 \%$ to $100 \%$ of patients and enhance spine stability, ${ }^{2}$ when it is applied alone or in cooperation with other treatments. $^{10-13}$ Besides, patients treated with PVP do not require much recovery as it is a small trauma, so it even can be used in patients with relative short-term life expectancy. However, the cement leakage is the first and most salient concern. It was reported that $9.2 \%$ to $41.0 \%$ of cement leakages were observed in patients with spine metastases treated with PVP. ${ }^{14-17}$ Although the majority of cement leakages would not lead to clinical symptoms, once the intra-spinal canal cement leakages occur, they could result in serious consequences. The intra-spinal canal cement leakages could cause devastating neurological deficits and thus patients might immediately need emergent open surgery. Besides, cement leakages into blood vessels have been observed to lead to pulmonary embolism and the incidence ranges from $4.6 \%$ to $23.0 \%{ }^{18}$ Therefore, making strategies to guide cement injections is really warranted.

Fortunately, there were some risk factors which were proved to be associated with cement leakages after PVP. A meta-analysis showed that the intravertebral cleft, cortical disruption, low cement viscosity, and a high volume of injected cement might lead to a higher rate of cement leakage after analyzing 22 studies. ${ }^{19}$ However, of all 22 studies, only one study specifically included patients with spine metastases, while other studies all included patients with osteoporotic vertebral compression fractures. Gabriel et al. ${ }^{20}$ found that vertebral collapse and cortical destruction were risk factors for cement leakages, and the history of prior treatment was a protective factor after analyzing 56 cancer patients and 81 vertebrae. Unfortunately, (1) the sample size included in the above-mentioned original studies was limited. Notably, when the sample size was not enough, the statistical power to gain the underlying answer would be not enough. (2) The majority of the above-mention studies were not specifically designed for analyzing patients with spine metastases. Compared with osteoporotic vertebral compression fractures, vertebral fractures resulted from spine metastases had a higher incidence of cement leakages because of the extensive destruction of the vertebral cortex and pedicle caused by metastatic tumors. This might lead to more intra-spinal canal cement leakages. ${ }^{21}$ Furthermore, (3) risk factors predicting cement leakages are still unclear due to a lack of uniform evaluations and limited data. ${ }^{19}$ More importantly, to our knowledge, (4) there is no data investigating risk factors for predicting specific intra-spinal canal cement leakages in patients with spine metastases. Besides, (5) there is no article proposing an algorithm that can predict cement injection volumes before performing PVP. Notably, it would be extremely helpful for selecting individual cement injection strategies in patients with spine metastases before treating with PVP.

Therefore, in this study, we aim to evaluate potential risk factors for intra-spinal canal cement leakages and further develop an algorithm to predict cement injection volumes in patients with spine metastases treated with PVP.

\section{Patients and Methods}

\section{Patients}

This study retrospectively included 251 patients and analyzed 584 vertebrae between Jan. 2010 to Aug. 2017 at the department of orthopedic surgery in Peking University First Hospital, Beijing, China. Inclusion Criteria: (1) spine metastases confirmed by pathology and supplied by MRI and/or CT scans; (2) patients with severe and intractable pains at the known level of vertebral sites; (3) osteolytic lesions; (4) metastatic vertebral tumors performed with PVP. Exclusion Criteria: (1) patients with primary cancers at spine; (2) patients with spinal cord and/or nerve root compression and Frankel grades decline or radiculopathy; (3) patients with vertebral fractures due to other diseases, such as trauma, osteoporosis, and/or angioma; (4) involved vertebrae with infections; (5) patients with uncorrectable coagulation disorders. The indication for PVP was determined by multidisciplinary cooperation, composing of neuroradiologists, neurosurgeons, and oncologists. All patients 
suffered from focal, severe, and intractable pain. The symptoms of patients were not relieved after conservative treatments or patients were too sick to undergo open surgery. For patients who underwent multiple-round PVP via separated operations, only the first round was analyzed. The Medical Research Ethics Board of the Peking University First Hospital approved the study protocol and waived patient's consent for review of medical records and images, because the aim of this study was to review existing practices and all data were anonymized and retrospective. This study was conducted in accordance with the Declaration of Helsinki.

\section{Clinical and Radiological Data}

Patients and vertebrae, in this study, were classified into three groups based on the grade of tumor invasion (typical case reports were shown in Figure 1). Patients with the complete posterior wall of vertebrae were classified into group A, patients without the complete posterior wall of vertebrae but with normal dural sac were classified into group B, and patients with deformation of the dural sac but without neurological symptom were classified into group C. Regarding clinical variables, we reviewed the medical records to assess age, gender, type of primary cancer, the number of vertebrae, treated vertebral segment, and cement volumes in the three groups. The type of primary cancer was classified into slow, moderate, and rapid growth, according to Tomita's classification. $^{22}$ Preoperative images (MRI and/or CT) were analyzed to determine the grade of tumor invasions. All patients underwent an X-ray or CT scan of the spine the day after the procedure.

\section{Therapeutic Interventions}

All operations were performed by three experienced spinal tumor surgeons. Patients were placed in a prone position for the procedure. Biopsy needle insertion and bone cement injection were carried out with the help of a C-arm X-ray machine (SIEMENS, Germany). After the administration of local anesthesia $(0.67 \%$ lidocaine and $0.34 \%$ ropivacaine), biopsy needles (Kinetic, China) were unilaterally or bilaterally transpedicular inserted into the anterior third of the vertebral body. Under normal conditions, the bilateral approach was preferred. A unilateral approach was chosen when more than 3 vertebrae need to be treated, and contralateral puncture was carried as the distribution of cement was not satisfactory or not symmetrical. Bone cement (Low viscosity, Tecres S.P.A., Italy), under X-ray guidance, was injected into the corresponding vertebral body. During its "toothpastelike" phase, four minutes after mixing, the cement was injected to minimize the potential risk of extravasation. The injection should be immediately stopped before doctors observed intra-spinal canal leakage under X-ray guidance and patients complained of neurological symptoms, which could be resulted from pressure on the posterior nerve. Furthermore, zoledronic acid (4 mg), diluting with $100 \mathrm{~mL} 0.9 \%$ sodium chloride and dripping slowly intravenously for 120 minutes, was
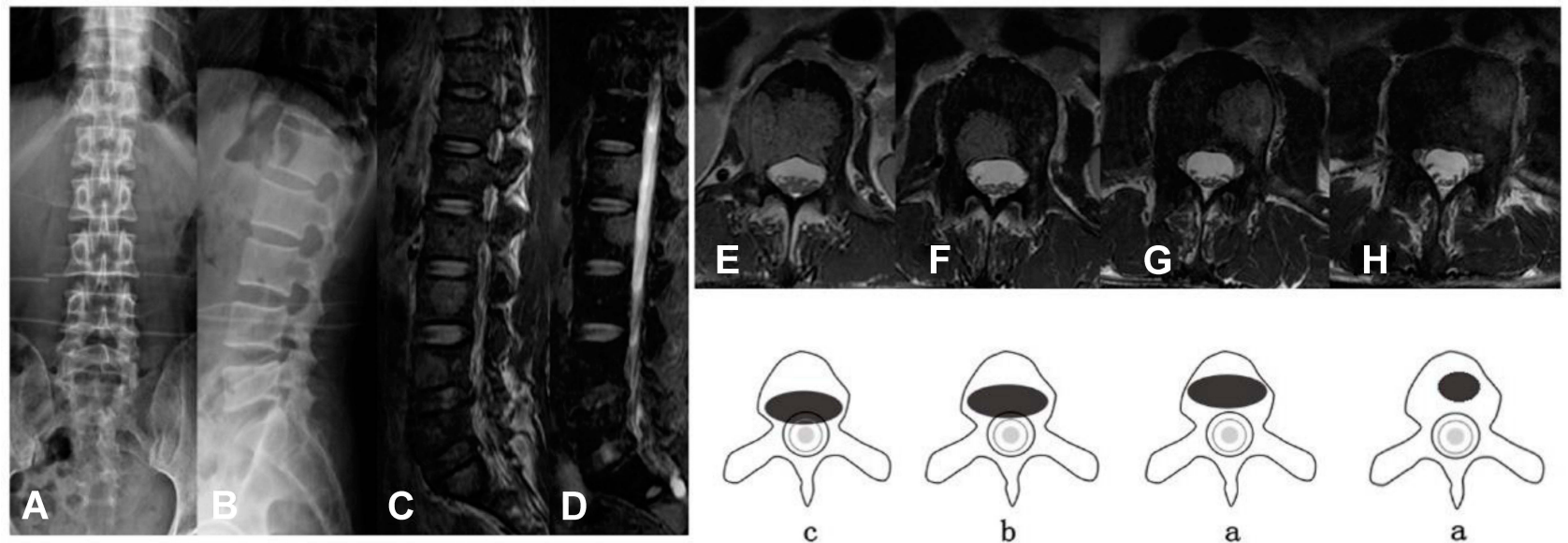

Figure I 53-year-old male with esophageal cancer. (A and B) Preoperative X-ray showed bone destruction at LI L4; (C and D) Preoperative MRI showed multiple spine metastases (LI L4); (E) MRI showed transversal spine metastases at LI, and it had deformation of the dural sac, but without spinal cord or nerve root compression; (F) MRI showed transversal spine metastases at L2, and it had epidural impingement, but without deformation of the dural sac; (G) MRI showed transversal spine metastases at L3, and it had complete posterior wall; $(\mathbf{H})$ MRI showed transversal spine metastases at $L 4$, and it had complete posterior wall. The pattern diagrams were shown just below the transversal MRI image of LI to L4. It indicated that LI was classified into group C, L2 was classified into group B, and L3 and L4 were classified into group A. And the patient was classified into group $\mathrm{C}$. 
performed on patients the next day after the operation. Zoledronic acid was injected once every 4 weeks for 12 months, if applicable.

\section{Safety and Outcome Evaluations}

Cement leakages were classified into two groups: (1) intraspinal canal leakage and (2) extra-spinal canal leakage, including leakages into paravertebral soft tissues and prevertebral and intervertebral spaces. We classified the cement leakages based on postoperative image data including X-rays or CT scans of the surgical vertebrae. Pain control and functional improvements were assessed using the visual analog score (VAS) ${ }^{23}$ and activity of daily living (ADL) evaluated by the Barthel Index, ${ }^{24}$ respectively. The Barthel Index is a 10-item measure of ADL. A higher Barthel index score indicates increased activity. The postoperative VAS scores and ADL were evaluated at the time of discharge, 3 months, and 6 months after surgery.

\section{Potential Risk Factors for Intra-Spinal Canal Cement Leakages}

Five potential risk factors were analyzed for predicting intra-spinal canal cement leakages, including treated vertebrae level (thoracic vs non-thoracic), vertebrae collapse ${ }^{20}$ (no collapse vs less than $50 \%$ vs more than $50 \%$ ), cortical osteolytic destruction in posterior wall (no vs yes), groups (group A vs group B vs group C), and Bilsky scale (0 vs 1 vs 2 vs 3 ). Vertebrae collapse and cortical osteolytic destruction in the posterior wall were reviewed in radiological data. Bilsky scale was an excellent tool to evaluate the severity of spinal cord compression due to metastatic cancers. ${ }^{25}$ Grade of 0 means bone-only disease, 1 indicates epidural impingement but without cord compression, 2 indicates spinal cord compression with cerebrospinal fluid around the cord, and 3 means spinal cord compression without cerebrospinal fluid visible around the cord.

\section{The Development of an Algorithm to Calculate Cement Injection Volumes}

The multiple linear regressions were performed to screen potential factors for predicting injected cement volumes. Those potential factors included treated vertebrae level (thoracic vs non-thoracic), vertebrae collapse ${ }^{20}$ (no collapse vs less than $50 \%$ vs more than $50 \%$ ), cortical osteolytic destruction in posterior wall (no vs yes), groups (group A vs group B vs group C), and Bilsky scale (0 vs 1 vs 2 vs 3 ). Significant variables were included in the algorithm, and the estimates of significant variables were used to create a formula: $\mathrm{Y}=$ estimates(a) $\mathrm{X} 1+$ estimates(b) $\mathrm{X} 2+$ estimates(c) $\mathrm{X} 3$ $+\ldots$ (Y indicates cement injection volumes and $\mathrm{X}$ indicates the significant variables that included in the algorithm). The scores of the included variables were assigned according to the original research data. For example, in our original research data, regarding the treated vertebrae level, thoracic vertebrae indicate 1 point and non-thoracic vertebrae indicate 0 points. Therefore, the score for thoracic vertebrae was 1 point and the non-thoracic vertebrae were 0 points. The total cement injection volumes of each patient were obtained from the formula.

\section{Statistical Analysis}

All statistical analyses were performed with the IBM SPSS Statistics 21 and SAS 9.2 software. Continuous variables were expressed as mean $\pm \mathrm{SD}$. The differences among the categorical variables between groups were analyzed using the linear-by-linear association, the chi-square test or the gamma test, and the rank-sum test. Repeated measures the correlated variance model across each time point were used to analyze the VAS outcome. The simple and multiple logistic regression models were performed to screen risk factors predicting intra-spinal canal cement leakage complications. The area under the receiver operating characteristic curve (AUROC) was performed to measure the significant variables. An AUROC value of more than 0.7 indicates useful variables and an AUROC value of more than 0.8 indicates good variables. The multiple linear regressions were performed to screen potential factors for predicting injected cement volumes. Significant variables were included in the algorithm, and the estimates of significant variables were used to create a formula. A P-value $<0.05$ was considered statistically significant (two-sided tests).

\section{Results}

\section{Basic Clinical Data of Patients and Vertebrae}

Five hundred and eighty-four vertebrae were enrolled in a total of 251 patients. The median age was 66 years old (range: 24-93 years old). All patients were classified into the three groups based on the grade of vertebrae with tumor invasion, and the number of patients in group $\mathrm{A}$ to $\mathrm{C}$ were 145,83 and 23, respectively. There were no statistically significant differences in age $(\mathrm{P}=0.488)$, gender $(\mathrm{P}=0.606)$, type of primary cancer $(\mathrm{P}=0.774)$, number of treated vertebrae $(\mathrm{P}=0.503)$, and injected bone cement $(\mathrm{P}=0.080)$ between the three groups (Table 1$)$. Five hundred 
eighty-four vertebrae were also divided into three groups, the number of vertebrae was 424 (group A), 132 (group B), 28 (group C), respectively. There was a significant difference in the level of spinal involvement among the three groups of vertebrae $(\mathrm{P}=0.006)$. In detail, spinal metastases with posterior wall involvement were more likely to occur at thoracic vertebrae and the rates were $42.5 \%, 53.8 \%$, and $60.7 \%$, respectively, in the three groups.

\section{Postoperative Pain and Functional Improvements}

The pre-operative VAS scores in the three groups were $7.24 \pm 1.37, \quad 7.44 \pm 1.53$ and $7.35 \pm 1.24$, respectively $(\mathrm{P}=0.575)$, and the scores decreased to $4.32 \pm 0.92,4.37$ \pm 1.01 , and $4.53 \pm 0.98$ at the time of discharge $(\mathrm{P}=0.104)$, $3.96 \pm 1.15,4.13 \pm 1.05$, and $3.94 \pm 0.64$ at postoperative 3 months $(\mathrm{P}=0.246)$, and $4.38 \pm 0.96,4.23 \pm 0.83$, and 4.15 \pm 1.06 at postoperative 6 months $(\mathrm{P}=0.327$, Figure 2$)$. In detail, 219/251 (87.3\%) patients had a decrease in VAS scores greater than 3 points after treatments. All patients had a complete function assessment, at the time of discharge, $22.1 \%(32 / 145)$ patients showed postoperative ADL improvement in the group A, 18.1\% (15/83) patients

Table I Preoperative Clinical Characteristics of Patients

\begin{tabular}{|c|c|c|c|c|}
\hline \multirow[t]{2}{*}{ Characteristics } & \multicolumn{3}{|l|}{ Groups } & \multirow[t]{2}{*}{$\mathbf{P}$} \\
\hline & $A(n=145)$ & $B(n=83)$ & $C(n=23)$ & \\
\hline Age (years) & $64.9 \pm 1.0$ & $64.1 \pm 1.5$ & $62.4 \pm 3.0$ & 0.488 \\
\hline \multicolumn{5}{|l|}{ Gender } \\
\hline Male & 87 & 45 & 12 & 0.606 \\
\hline Female & 58 & 38 & 11 & \\
\hline \multicolumn{5}{|l|}{ Type of Primary Cancer } \\
\hline Slow & 38 & 26 & 5 & 0.774 \\
\hline Middle & 19 & 13 & 3 & \\
\hline Fast & 88 & 44 & 15 & \\
\hline \multicolumn{5}{|l|}{ The Number of Vertebrae } \\
\hline Single & 64 & 30 & 10 & 0.503 \\
\hline Multiple & 81 & 53 & 13 & \\
\hline $\begin{array}{l}\text { Injected bone cement } \\
\text { volume }(\mathrm{mL})\end{array}$ & $2.8 \pm 0.1$ & $3.2 \pm 0.1$ & $2.6 \pm 0.3$ & 0.080 \\
\hline \multicolumn{5}{|l|}{ Treated Vertebrae Level* } \\
\hline Cervical & II (2.6\%) & $2(1.5 \%)$ & $0(0.0 \%)$ & 0.006 \\
\hline Upper thoracic & 49 (11.5\%) & 27 (20.5\%) & $6(21.4 \%)$ & \\
\hline Lower thoracic & $13 \mid(30.9 \%)$ & 44 (33.3\%) & II (39.3\%) & \\
\hline Lumbar & 195 (46.0\%) & $58(43.9 \%)$ & $9(32.1 \%)$ & \\
\hline Sacrum & 38 (9.0\%) & I (0.8\%) & $2(7.2 \%)$ & \\
\hline
\end{tabular}

Note: *Indicating 584 treated vertebrae.

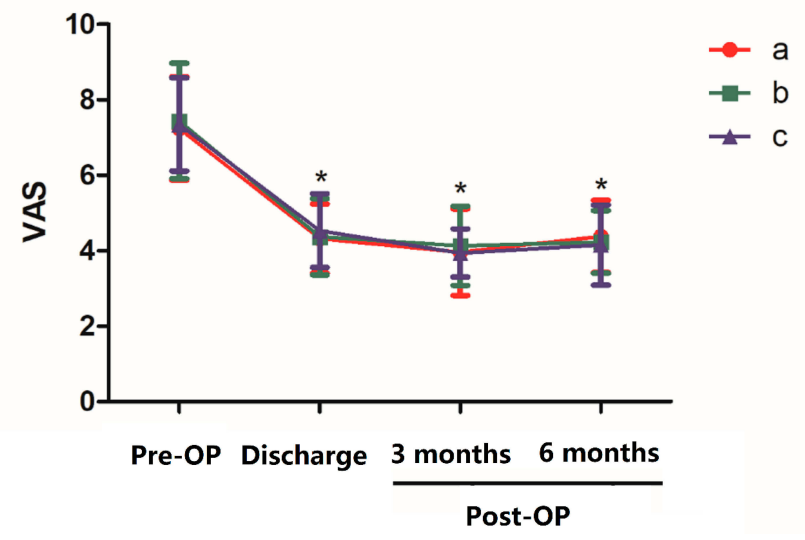

Figure 2 VAS in the three groups before and after surgery (* indicates $P<0.01$, as compared with pre-operative VAS.

Abbreviation: Pre-OP, pre-operation; Post-OP, post-operation.

had postoperative ADL improvement in the group $\mathrm{B}$, and $21.7 \%(5 / 23)$ patients in the group $\mathrm{C}(\mathrm{P}=0.676$, Table 2$)$. Postoperative ADL improvements also showed no significant difference among the three groups at 3 months $(\mathrm{P}=0.687)$ and 6 months $(\mathrm{P}=0.759)$.

\section{Cement Leakages}

In the 584 vertebrae, cement leakages occurred in 100 vertebrae (17.1\%). In detail, extra-spinal canal leakage occurred in 88 vertebrae $(15.1 \%)$, and intra-spinal canal leakage occurred in 12 vertebrae $(2.1 \%)$. Among all patients with cement leakages, one patient in group $\mathrm{B}$ complained of heated feeling in the lower extremity during operation, and cement injection was immediately stopped. After intravenous application of $5 \mathrm{mg}$ dexamethasone, the symptoms gradually relieved. All patients had no neurological symptoms associated with cement leakages after surgery. There were statistical differences in cement leakages among the three groups $(\mathrm{P}<0.001$, Table 3$)$. Group $\mathrm{C}(28.6 \%)$ had the highest leakage rate than group $\mathrm{A}(14.4 \%)$ and $\mathrm{B}(23.5 \%)(\mathrm{P}=0.014)$. Namely, vertebras in group $\mathrm{C}$ were more prone to intraspinal canal leakage (A case report was shown in Figure 3), as compared with vertebrae in group A and B. In detail, $14.3 \%(4 / 28)$ vertebrae in group $C$ had intra-spinal canal leakage, while $1.2 \%(5 / 424)$ vertebrae in group $\mathrm{A}$ and $2.3 \%$ $(3 / 132)$ vertebrae in group B had this complication.

\section{Risk Factors for Intra-Spinal Canal Cement Leakages}

In the simple logistic regression model, vertebrae collapse ( $\mathrm{OR}=2.28$, 95\% CI: $1.10-4.72, \mathrm{P}=0.03$, Table 4), groups $(\mathrm{OR}=3.59,95 \% \mathrm{CI}: 1.70-7.60, \mathrm{P}<0.001)$, and Bilsky scale 
Table 2 Postoperative Pain and Function Improvements

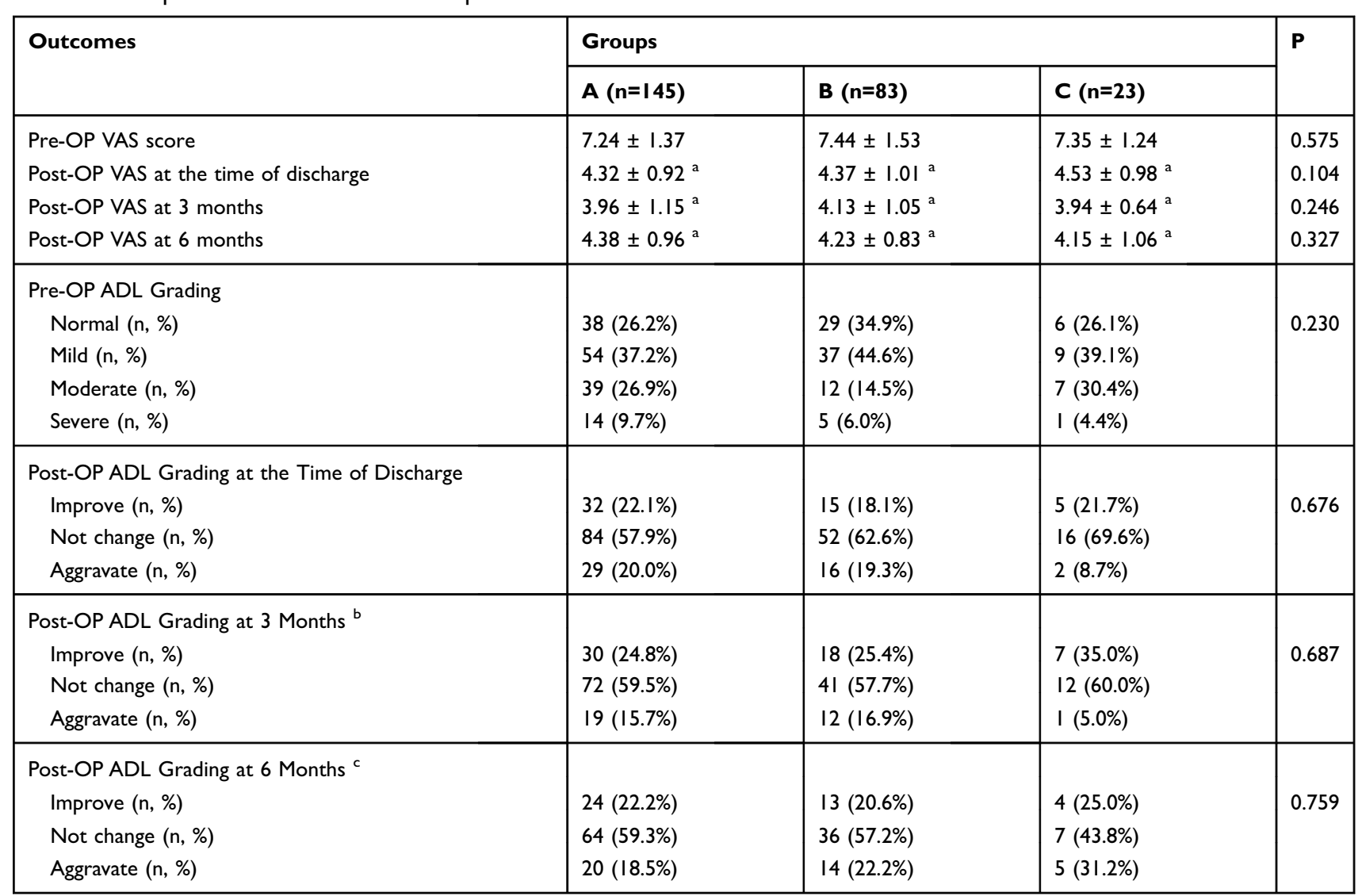

Notes: ${ }^{2}$ As compared with pre-operative VAS, all $\mathrm{P}<0.01$. Pre-OP, indicating pre-operative; Post-OP, indicating post-operative; VAS, indicating visual analogy score; $A D L$, indicating activity of daily living. ${ }^{b} 24$ patients died in group A, 12 patients died in group B, and 3 patients died in group C; ${ }^{c} 37$ patients died in group A, 20 patients died in group B, and 9 patients died in group $\mathrm{C}$.

Table 3 Cement Leakage Distribution in Different Groups of Vertebrae

\begin{tabular}{|l|l|l|l|l|l|}
\hline \multicolumn{2}{|l|}{$\begin{array}{l}\text { Cement Leakage and } \\
\text { Position }\end{array}$} & \multicolumn{2}{|l|}{ Groups } & P \\
\cline { 2 - 5 } & A (n=424) & B (n=132) & C (n=28) & \\
\hline Leakages & $\begin{array}{l}\text { No } \\
\text { Yes }\end{array}$ & $\begin{array}{l}363(85.6 \%) \\
61(14.4 \%)\end{array}$ & $\begin{array}{l}101(76.5 \%) \\
31(23.5 \%)\end{array}$ & $\begin{array}{l}20(71.4 \%) \\
8(28.6 \%)\end{array}$ & 0.014 \\
\hline Positions & $\begin{array}{l}\text { Extra-spinal } \\
\text { canal } \\
\end{array}$ & $56(91.8 \%)$ & $28(90.3 \%)$ & $4(50.0 \%)$ & 0.003 \\
& $\begin{array}{l}\text { Intra-spinal } \\
\text { canal }\end{array}$ & $5(8.2 \%)$ & $3(9.7 \%)$ & $4(50.0 \%)$ & \\
\hline
\end{tabular}

$(\mathrm{OR}=3.34,95 \% \mathrm{CI}: 1.90-5.87, \mathrm{P}<0.001)$ were significantly associated with intra-spinal canal cement leakages. However, in the multiple logistic analysis, only the Bilsky scale $(\mathrm{OR}=3.34,95 \% \mathrm{CI}: 1.90-5.87, \mathrm{P}<0.001)$ maintained significance, and the other two variables were not significant with intra-spinal canal cement leakages. In detail, in vertebrae with a Bilsky scale of 2, 12.5\% (3/24) of them occurred intra-spinal canal cement leakages and $25.0 \%$ (1/4) of vertebrae with a Bilsky scale of 3 suffered this complication, while only
$1.14 \%(6 / 525)$ of vertebrae with a Bilsky scale of 0 and $6.45 \%(2 / 31)$ with a Bilsky scale of 1 had intra-spinal canal cement leakages. The AUROC value for the variable of vertebrae collapse alone was 0.60 (Figure 4), the variable of groups alone was 0.69, and Bilsky scale alone was 0.71. When the three variables combined, the AUROC value could increase to 0.73 .

\section{An Algorithm to Calculate Cement Injection Volumes}

The multiple linear regression analysis showed that treated vertebrae level (estimate value: 0.8677, $\mathrm{P}<0.001$ ), cortical osteolytic destruction in posterior wall (estimate value: $0.6182, \mathrm{P}<0.001$ ), and Bilsky scale (estimate value: 0.2819, $\mathrm{P}=0.014)$ were significantly associated with injected cement volumes (Table 5). Besides, the intercept was significant (estimate value: $3.1627, \mathrm{P}<0.001$ ). Therefore, the abovementioned three variables and the intercept were used to develop an algorithm: $Y=3.1627-0.8677 \times$ treated vertebrae level $-0.6182 \times$ cortical osteolytic destruction in posterior 

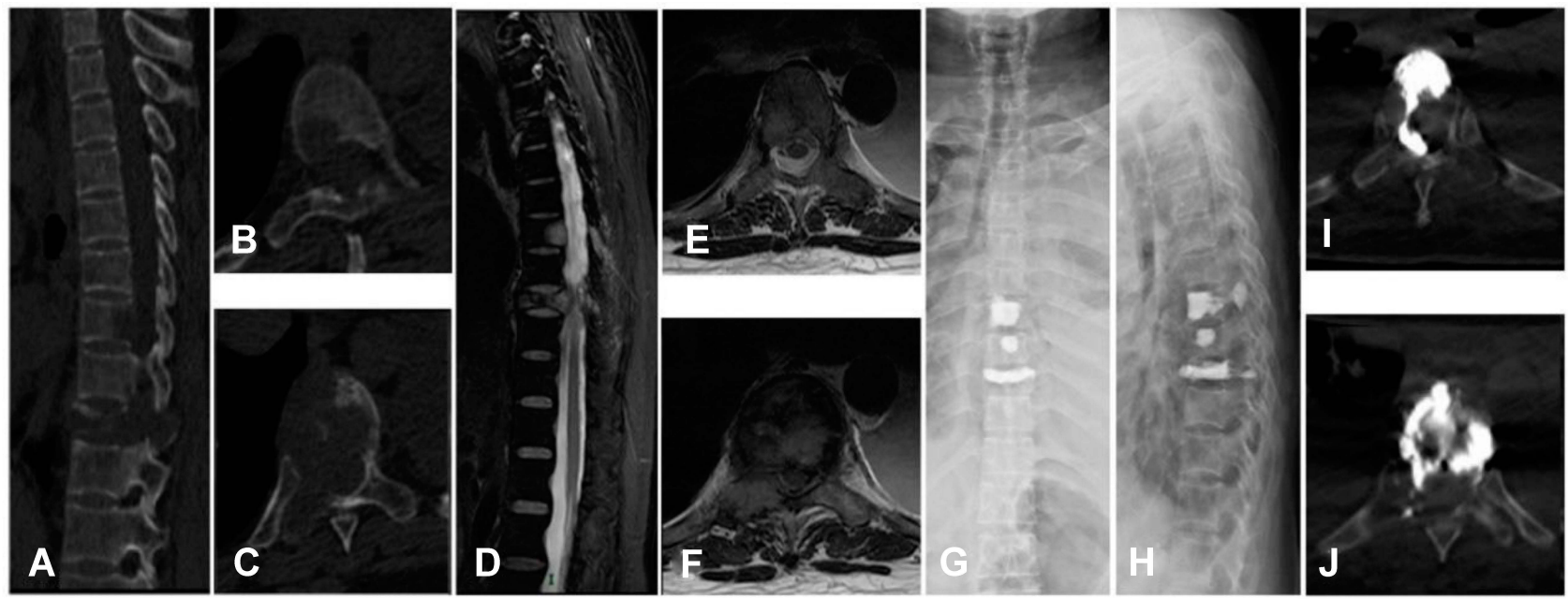

Figure 3 A 59-year-old male with lung cancer who treated with PVP suffered from intra-spinal canal cement leakage. (A) CT sagittal plane showed T8 and TI0 destructions; (B) CT horizontal plane of T8; (C) CT horizontal plane of TI0; (D) MRI sagittal plane showed T8 metastatic lesion and TI0 metastatic spinal cord compression; (E) MRI horizontal plane of T8; (F) MRI horizontal plane of TI0; (G and H) postoperative X-ray; (I) CT horizontal plane of T8 showed intra-spinal canal cement leakage; (J) CT horizontal plane of TIO showed intra-spinal canal cement leakage.

wall $-0.2819 \times$ Bilsky scale. (Figure 5) showed the residual plot for fitting the effectiveness of multiple linear regressions. Surgeons can use the algorithm to calculate cement injection volumes. For example, if a patient with thoracic (1 point) vertebrae metastases had cortical osteolytic destructions in posterior wall (1 point) and a Bilsky scale of 2 ( 2 points), then the predicted cement injection was 3.1627 $-0.8677 \times 1-0.6182 \times 1-0.2819 \times 2=1.113 \mathrm{~mL} \approx 1.1 \mathrm{~mL}$. The scores for each significant variable were shown in (Table 5).

\section{Discussion}

\section{The Efficacy of PVP}

PVP is an important minimally invasive technique in the treatment of spine metastases. It can effectively relieve back pain and enhance the stability of the spine, and thus this technique is widely performed in patients with vertebral body compression fractures due to metastatic cancer and osteoporosis [10,11,12.13]. However, tumors invade the posterior wall of the vertebral body has long been accepted as a relative contraindication to PVP because of the risk of intra-spinal canal leakages. ${ }^{26,27}$ To date, only a few studies have reported the use of PVP in patients with posterior spine involvement, and the number of spinal metastases patients included in the studies was limited. ${ }^{22,28-30}$ Therefore, we first evaluated the efficacy and safety of PVP which was used to treat spinal metastases with posterior wall involvement in a large number of patients. In this study, patients and vertebrae were divided into three groups based on the grade of tumor invasion, and a systematic therapeutic comparison was achieved among the three groups.

In the present study, 584 vertebrae were evaluated in 251 patients. Patients were classified into 3 groups based on the grade of tumor invasion. There was no statistical significance in age, gender, type of primary cancer, the number of treated vertebrae, and injected bone cement volumes among the three groups. This indicated that those variables were similarly distributed. However, spinal metastases with posterior wall involvement were more likely to occur at the thoracic spine $(\mathrm{P}=0.006)$. In patients with posterior wall involvement (group B and C), vertebroplasty was performed in $88(55.0 \%)$ thoracic and 67 $(41.9 \%)$ lumbar. In the study analyzed by Amoretti et al. ${ }^{31}$ PVP was conducted in 54\% thoracic and $41 \%$ lumbar, which was similar to our study. Regarding pain outcome, all postoperative VAS scores were lower than preoperative VAS scores, which indicated that PVP could truly achieve good pain relief in all three groups. However, there was no statistical significance in VAS scores and ADL improvements between the three groups after surgery $(\mathrm{P}>0.05)$. These results indicated patients obtained similar pain relief and function improvement after the treatment of PVP regardless of the grade of tumor invasions, which were consistent with the previous study. ${ }^{28}$ Shimony et al. ${ }^{28}$ retrospectively analyzed 50 patients with epidural involvement who received PVP treatment. On the basis of the degree of spinal canal compromise, patients have also 
Table 4 Risk Factors for Intra-Spinal Canal Cement Leakage

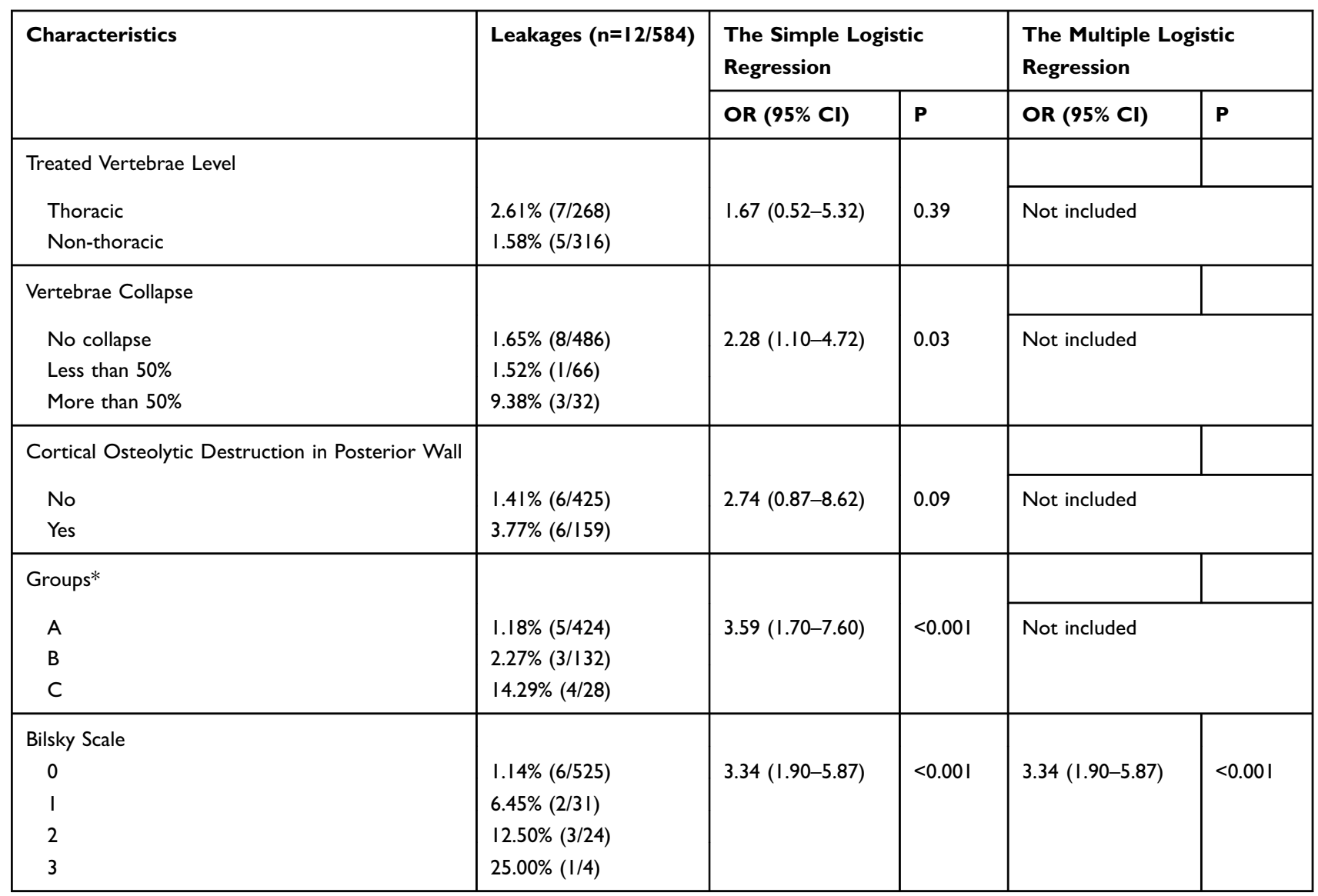

Notes: *Indicates vertebrae with complete posterior wall of vertebrae were classified into group A, vertebrae without complete posterior wall of vertebrae but with normal Dural sac were classified into group B, and vertebrae with deformation of the Dural sac but without neurological symptom.

Abbreviations: $\mathrm{OR}$, odds ratio; $\mathrm{Cl}$, confident interval.

divided into three groups: patients in the first group had no epidural involvement, the second group had mild epidural involvement without contact with spinal cord or nerve roots, and the third group had moderate involvement and contact with spinal cord or nerve roots. In the study, $82 \%$ of patients had improved postoperative pain and $52 \%$ of patients had improved postoperative mobility. The study found no significant difference in pain or mobility outcomes among the three groups either. Appel et al. ${ }^{22}$ showed similar results in a series of 23 patients (Seven patients with spine metastases), but this study did not evaluate functional improvements. Postoperative functional improvement could be influenced to some extent by the assessment scale. The postoperative functional improvement rate is relatively lower in our study mainly due to the large span and low resolution of the Barthel Index. Bae et al. ${ }^{32}$ reported that PVP reduced Karnofsky performance status (KPS) in spinal metastases patients, and the improvement rate was $35 \%$. Fourney et al. ${ }^{17}$ reported functional outcome using Frankel grade, only
$15 \%$ of patients improved, which was similar to our results ( $20.7 \%$ of patients improved at the time of discharge).

\section{Cement Leakages in PVP}

In the 584 vertebrae, cement leakages occurred in 100 vertebrae (17.1\%). In detail, extra-spinal canal leakages occurred in 88 vertebrae (15.1\%) and intra-spinal canal leakages occurred in 12 vertebrae $(2.1 \%)$. According to other studies, $9.2 \%$ to $41.0 \%$ of cement leakages were observed in patients with spine metastases treated with PVP. ${ }^{14-17}$ The majority of cement leakages are asymptomatic, and approximately $5 \%$ of cement leakages have transient neurological deficits, but most symptoms will be disappeared without additional surgery within one month. ${ }^{33}$ The neurological deficits mainly resulted from posterior cement that leaks into the spinal column. This may cause devastating neurological deficits necessitating emergent open neurosurgery. Posterior wall involvement was regarded as a relative contraindication to PVP mainly because of the high risk of intra-spinal canal leakage. 


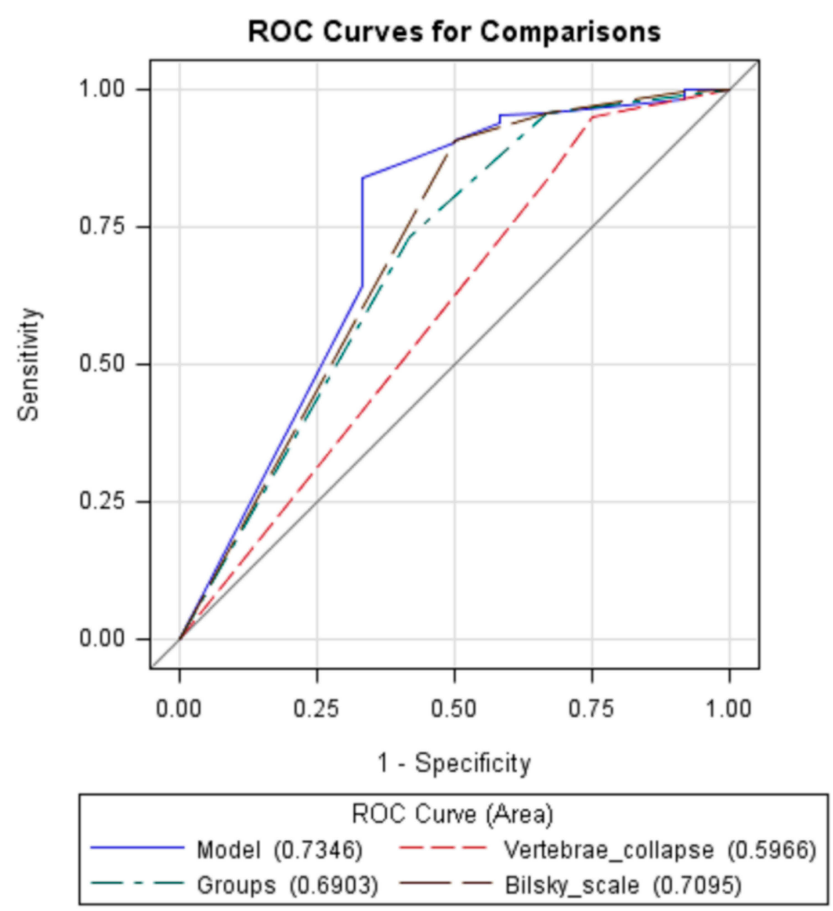

Figure 4 ROC curves for variables of vertebrae collapse (ROC $=0.60$ ), groups $(\mathrm{ROC}=0.69)$, Bilsky scale $(\mathrm{ROC}=0.7 \mathrm{I})$, and model including all the three significant factors $(\mathrm{ROC}=0.73)$.

Shimony et al. ${ }^{28}$ found that there was an inclination: The higher rates of intra-spinal canal leakages tended to occur in more serious posterior wall involvements. But the difference in rates of intra-spinal canal leakages was not statistically due to the limited sample size. Sun et al. ${ }^{30}$ and Saliou et al. ${ }^{29}$ reported that PVP was safe in patients with posterior wall involvement with low complication rates. However, patients were not classified depend on the grade of posterior wall involvements.

In the present study, vertebrae in group C $(28.6 \%)$ had the highest rate of cement leakages than patients in group A (14.4\%) and B (23.5\%) $(\mathrm{P}=0.014)$. Besides, vertebrae in group $\mathrm{C}(14.3 \%)$ were more prone to intra-spinal canal leakage, as compared with vertebrae in group A (1.2\%) and B (2.3\%). Among the 12 intra-spinal canal leakages, only one had clinical symptoms and the patient complained of fever in the lower extremity during operation. The symptoms gradually relieved after stopping the injection and intravenous application of dexamethasone. As the grade of tumor invasion increased, the rate of intraspinal canal leakages was increasing, ranging from $1.2 \%$ (5/424) to $14.3 \%$ (4/28). Although spinal cord compression or nerve root compression caused by intra-spinal canal leakage did not appear in our study, once it appeared, subsequent treatments would be complicated.
Table 5 An Algorithm to Calculate Injected Bone Cement Volumes

\begin{tabular}{|c|c|c|c|c|}
\hline \multirow[t]{2}{*}{ Characteristics } & \multirow[t]{2}{*}{$\begin{array}{l}\text { Cement } \\
(\mathrm{mL})\end{array}$} & \multirow[t]{2}{*}{ Scores } & \multicolumn{2}{|c|}{$\begin{array}{l}\text { The Multiple Linear } \\
\text { Regression }\end{array}$} \\
\hline & & & OR $(95 \% \mathrm{Cl})$ & $\mathbf{P}$ \\
\hline Intercept & & & 3.1627 & $<0.001$ \\
\hline $\begin{array}{l}\text { Treated Vertebrae Level } \\
\text { Thoracic } \\
\text { Non-thoracic }\end{array}$ & $\begin{array}{l}2.44 \\
3.27\end{array}$ & & -0.8677 & $<0.001$ \\
\hline Vertebrae collapse & & & & \\
\hline $\begin{array}{l}\text { No collapse } \\
\text { Less than } 50 \% \\
\text { More than } 50 \%\end{array}$ & $\begin{array}{l}2.87 \\
3.20 \\
2.59\end{array}$ & $\begin{array}{l}1 \\
2 \\
3\end{array}$ & Not included & \\
\hline $\begin{array}{l}\text { Cortical Osteolytic } \\
\text { Destruction in Posterior } \\
\text { Wall } \\
\text { No } \\
\text { Yes }\end{array}$ & $\begin{array}{l}3.15 \\
2.79\end{array}$ & $\begin{array}{l}0 \\
1\end{array}$ & -0.6182 & $<0.001$ \\
\hline Groups* & & & & \\
\hline $\begin{array}{l}\text { A } \\
\text { B } \\
\text { C }\end{array}$ & $\begin{array}{l}2.80 \\
3.23 \\
2.64\end{array}$ & $\begin{array}{l}1 \\
2 \\
3\end{array}$ & Not included & \\
\hline $\begin{array}{l}\text { Bilsky Scale } \\
0 \\
1 \\
2 \\
3\end{array}$ & $\begin{array}{l}2.89 \\
3.11 \\
2.79 \\
1.75\end{array}$ & $\begin{array}{l}0 \\
1 \\
2 \\
3\end{array}$ & -0.2819 & 0.014 \\
\hline
\end{tabular}

Notes: Model: $Y=3.1627-0.8677 \times$ treated vertebrae level $-0.6182 \times$ cortical osteolytic destruction in posterior wall $-0.2819 \times$ Bilsky scale. *Indicates vertebrae with complete posterior wall of vertebrae were classified into group $A$, vertebrae without complete posterior wall of vertebrae but with normal Dural sac were classified into group B, and vertebrae with deformation of the Dural sac but without neurological symptom.

Abbreviations: $\mathrm{OR}$, odds ratio; $\mathrm{Cl}$, confident interval.

Therefore, we did not recommend routine PVP in the treatment of patients in group $\mathrm{C}$ unless the patient had intractable pain, few other therapeutic options, and a short life expectancy.

\section{The Risk Factors for Intra-Spinal Canal Cement Leakages}

Several studies have investigated potential risk factors for cement leakages. Gabriel et al. ${ }^{20}$ found that vertebral collapse and cortical destruction were risk factors for cement leakage and history of prior treatment was a protective factor after analyzing 56 cancer patients with spine metastases. ToméBermejo et al. ${ }^{34}$ found that the location at the thoracolumbar level and the absence of Kummell disease were strong 


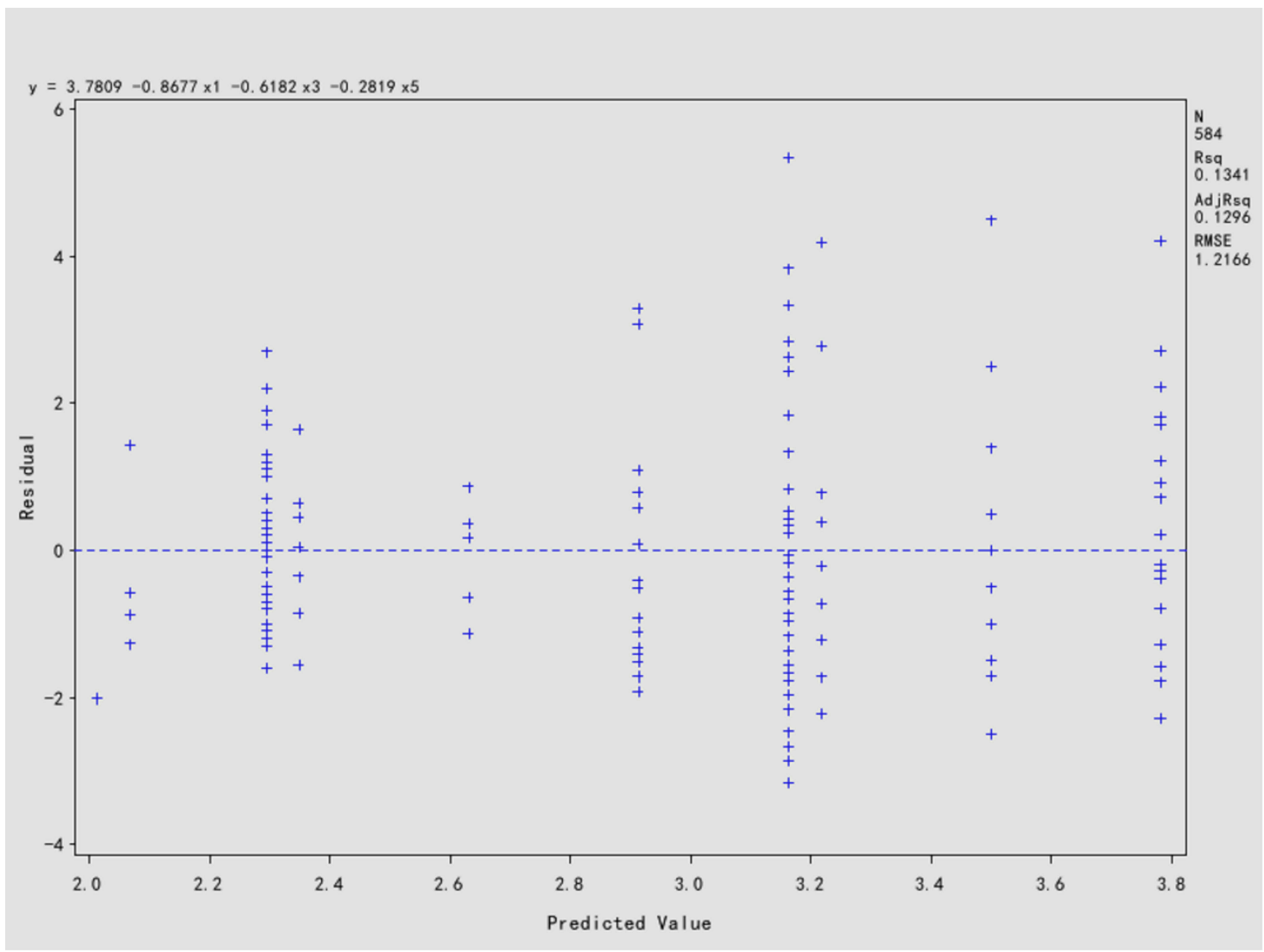

Figure 5 Residual plot for fitting effectiveness of multiple linear regression: The formula was $Y=3.1627-0.8677 \times$ treated vertebrae level $(x \mid)-0.6182 \times$ cortical osteolytic destruction in posterior wall $(\times 3)-0.2819 \times$ Bilsky scale $(\times 5)$.

predictive factors for cement leakages after analyzing 194 patients who with painful osteoporotic or malignant vertebral fracture (spine metastases, $\mathrm{n}=18$ ). Zhu et al. ${ }^{35}$ found that higher fracture severity grade and larger volume of bone cement were significantly associated with cement leakage after analyzing 485 patients treated with PVP (spine metastases, $\mathrm{n}=50$ ). However, (1) the above-mentioned studies were not exclusively included patients with spine metastases. Compared with an osteoporotic vertebral compression fracture, vertebral fracture resulted from spine metastases had a higher incidence of cement leakages because of the extensive destruction of the vertebral cortex and pedicle caused by cancers, which might lead to more intra-spinal canal cement leakages. ${ }^{21}$ Besides, (2) those variables were analyzed for cement leakages not especially for intra-spinal canal cement leakages. Intra-spinal canal cement leakages are a much more serious complication. The risk factors especially for predicting intra-spinal canal cement leakages remain unclear due to limited data. In this study, we found that the Bilsky scale was an independent variable for intra-spinal canal cement leakages. Furthermore, the AUROC value for the variable of the Bilsky scale alone was 0.71 , which indicated that the variable was a useful factor to predict intra-spinal canal cement leakages. In detail, among patients with a Bilsky scale of 2, 12.5\% (3/24) patients occurred intraspinal canal cement leakage, and up to $25.0 \%$ (1/4) patients who had a Bilsky scale of 3 suffered this complication. Therefore, we also recommended that PVP should not be performed in those patients with a Bilsky scale of 2 or 3 to prevent risks of intra-spinal canal cement leakages.

\section{An Algorithm Calculating Cement Injection Volume}

It would be extremely helpful for selecting individual therapeutic strategies in patients with spine metastases according to the prediction of prognosis. Previously, in 2016, we proposed an algorithm to predict survival and function outcomes in patients with spine metastases after decompressive surgery in a series of 206 patients. ${ }^{9}$ This model can guide surgeons to choose appropriate surgical candidates according to the stratification of patients at different risk of poor survival and function outcomes. 
Similarly, the stratification of patients at high risk of intraspinal canal cement leakages would be of great help to guide clinical decision-making, and medical interventions could be performed in advance. Namely, an algorithm to predict injected cement volume could provide important information for guiding cement injection in PVP. However, to our best knowledge, there was no algorithm that can predict cement injection volume in patients with spine metastases treated with PVP.

Therefore, in the present study, we also aim to propose an algorithm that can predict cement injection volume in patients with spine metastatic diseases. We found that the treated vertebrae level, cortical osteolytic destruction in the posterior wall, and the Bilsky scale were significantly associated with injected cement volume. Consequently, those factors were included in the algorithm. Based on the estimates of each significant factor, an algorithm was developed: $\mathrm{Y}=3.1627$ (the intercept) $-0.8677 \times$ treated vertebrae level $-0.6182 \times$ cortical osteolytic destruction in posterior wall $-0.2819 \times$ Bilsky scale. The scores for each significant variable were assigned according to the original research data. For example, regarding the treated vertebrae level, 1 point indicates thoracic vertebrae and 0 points indicate non-thoracic vertebrae. Finally, the formula was successfully created. As far as we could concern, this algorithm was the first model that could be used to predict cement injection volumes in patients with spine metastases treating with PVP. We could use the corresponding scores to calculate the injection volume, which could subsequently be used as a reference to guide cement injection during PVP. An example of how to use this formula was given in the result section.

\section{Limitations}

We acknowledged the limitations of our study. Firstly, although it included a relatively large number of patients and a comprehensive analysis of all data was performed, it was limited by its retrospective nature. Secondly, as compared with MRI (preoperative) and X-ray (postoperative), CT scans that were available to us were limited. Ideally, it would be better to have both types of images available preand postoperative for every patient to help decide the grouping of patients and cement leakage type. Thirdly, this algorithm was developed based on patients with spine metastases, so it is not applicable in patients with vertebrae compression fracture due to osteoporosis. Lastly, some variables such as viscosity and size of vertebrae were not collected in this study. This may lead to selection bias. Therefore, although we identified risk factors for intra-spinal canal cement leakages and developed an algorithm to calculate cement injection volumes, further investigations were still warranted. The validation of the risk factors for intra-spinal canal cements leakages and the algorithm needs to be further confirmed by prospective studies from multiple medical centers. After the validation and revision of the algorithm, it would be very interesting and necessary to develop relevant software programs or websites to guide medical practice.

\section{Conclusions}

In conclusion, an algorithm is proposed and can be used to calculate cement injection volumes in spine metastases treated with PVP. This algorithm can facilitate surgical planning and guide cement injection. Bilsky scale is an independent risk factor for intra-spinal canal cement leakages. We do not recommend PVP treated in patients with a Bilsky scale of 2 and 3 mainly due to high rates of intraspinal canal cement leakages.

\section{Funding}

This study was supported by the Medical and health science and technology innovation project of Sanya (NO. 2018YW04).

\section{Disclosure}

The authors report no conflicts of interest in this work.

\section{References}

1. Torre LA, Trabert B, DeSantis CE, et al. Ovarian cancer statistics, 2018. CA Cancer J Clin. 2018;68(4):284-296. doi:10.3322/caac.21456

2. Stephenson MB, Glaenzer B, Malamis A. Percutaneous minimally invasive techniques in the treatment of spinal metastases. Curr Treat Options Oncol. 2016;17(11):56. doi:10.1007/s11864-016-0433-1

3. Facchini G, Di Tullio P, Battaglia M, et al. Palliative embolization for metastases of the spine. Eur J Orthop Surg Traumatol. 2016;26 (3):247-252. doi:10.1007/s00590-015-1726-y

4. Sohn S, Kim J, Chung CK, et al. A nationwide epidemiological study of newly diagnosed spine metastasis in the adult Korean population. Spine J. 2016;16(8):937-945. doi:10.1016/j.spinee.2016.03.006

5. von Moos R, Costa L, Ripamonti CI, Niepel D, Santini D. Improving quality of life in patients with advanced cancer: targeting metastatic bone pain. Eur J Cancer. 2017;71:80-94. doi:10.1016/j.ejca.2016.10.021

6. Sohn S, Chung CK, Han KD, et al. A nationwide study of surgery in a newly diagnosed spine metastasis population. J Korean Neurosurg Soc. 2018.

7. Sailhan F, Prost S, Zairi F, et al. Retrospective multicenter study by the French Spine society of surgical treatment for spinal metastasis in France. Orthop Traumatol Surg Res. 2018;104(5):589-595. doi:10. 1016/j.otsr.2018.06.006

8. Patchell RA, Tibbs PA, Regine WF, et al. Direct decompressive surgical resection in the treatment of spinal cord compression caused by metastatic cancer: a randomised trial. Lancet. 2005;366 (9486):643-648. doi:10.1016/S0140-6736(05)66954-1 
9. Lei M, Li J, Liu Y, Jiang W, Liu S, Zhou S. Who are the best candidates for decompressive surgery and spine stabilization in patients with metastatic spinal cord compression?: a new scoring system. Spine. 2016;41 (18):1469-1476. doi:10.1097/BRS.0000000000001538

10. Berenson J, Pflugmacher R, Jarzem P, et al. Cancer patient fracture evaluation i: balloon kyphoplasty versus non-surgical fracture management for treatment of painful vertebral body compression fractures in patients with cancer: a multicentre, randomised controlled trial. Lancet Oncol. 2011;12(3):225-235. doi:10.1016/S1470-2045(11)70008-0

11. Spratt DE, Beeler WH, de Moraes FY, et al. An integrated multidisciplinary algorithm for the management of spinal metastases: an international spine oncology consortium report. Lancet Oncol. 2017;18(12):e720-e730. doi:10.1016/S1470-2045(17)30612-5

12. Bludau F, Welzel G, Reis T, et al. Phase I/II trial of combined kyphoplasty and intraoperative radiotherapy in spinal metastases. Spine J. 2018;18(5):776-781. doi:10.1016/j.spinee.2017.09.011

13. Zhang J, Wang Y, Han K, et al. Percutaneous vertebroplasty combined with zoledronic acid for the treatment of painful osteolytic spinal metastases in patients with breast cancer. J Vasc Interv Radiol. 2013;24(12):1861-1867. doi:10.1016/j. jvir.2013.08.023

14. Zhang JJ, Zhou Y, Hu HY, et al. Safety and efficacy of multilevel vertebroplasty for painful osteolytic spinal metastases: a single-centre experience. Eur Radiol. 2017;27(8):3436-3442. doi:10.1007/s00330016-4683-x

15. Tian QH, Sun XQ, Lu YY, et al. Percutaneous vertebroplasty for palliative treatment of painful osteoblastic spinal metastases: a single-center experience. J Vasc Interv Radiol. 2016;27(9):1420-1424. doi:10.1016/j.jvir.2016.04.033

16. Hulme PA, Krebs J, Ferguson SJ, Berlemann U. Vertebroplasty and kyphoplasty: a systematic review of 69 clinical studies. Spine. 2006;31(17):1983-2001. doi:10.1097/01.brs.0000229254.89952.6b

17. Fourney DR, Schomer DF, Nader R, et al. Percutaneous vertebroplasty and kyphoplasty for painful vertebral body fractures in cancer patients. J Neurosurg. 2003;98(1 Suppl):21-30. doi:10.3171/spi.2003.98.1.0021

18. Kim YJ, Lee JW, Park KW, et al. Pulmonary cement embolism after percutaneous vertebroplasty in osteoporotic vertebral compression fractures: incidence, characteristics, and risk factors. Radiology. 2009;251(1):250-259. doi:10.1148/radiol.2511080854

19. Zhan Y, Jiang J, Liao H, Tan H, Yang K. Risk factors for cement leakage after vertebroplasty or kyphoplasty: a meta-analysis of published evidence. World Neurosurg. 2017;101:633-642. doi:10.1016/j. wneu.2017.01.124

20. Gabriel C, Jonathan D, Charles M, et al. Cement leakage in percutaneous vertebroplasty for spinal metastases: a retrospective evaluation of incidence and risk factors. Spine. 2014;39(5):332-338. doi:10.1097/BRS.0000000000000134

21. Zhang HR, Xu MY, Yang XG, Qiao RQ, Li JK, Hu YC. Percutaneous vertebral augmentation procedures in the management of spinal metastases. Cancer Lett. 2020;475:136-142. doi:10.1016/j.canlet.2020. 01.038
22. Appel NB, Gilula LA. Percutaneous vertebroplasty in patients with spinal canal compromise. AJR Am J Roentgenol. 2004;182 (4):947-951. doi:10.2214/ajr.182.4.1820947

23. Hamill-Ruth RJ, Marohn ML. Evaluation of pain in the critically ill patient. Crit Care Clin. 1999;15(1):35-54. doi:10.1016/S07490704(05)70038-5

24. Rollnik JD. [Barthel index as a length of stay predictor in neurological rehabilitation]. Rehabilitation. 2009;48(2):91-94. German. doi:10.1055/s-0029-1202294

25. Bilsky MH, Ilya L, Fourney DR, et al. Reliability analysis of the epidural spinal cord compression scale. J Neurosurg Spine. 2010;13 (3):324-328. doi:10.3171/2010.3.SPINE09459

26. Kaemmerlen P, Thiesse P, Jonas $\mathrm{P}$, et al. Percutaneous injection of orthopedic cement in metastatic vertebral lesions. $N$ Engl $\mathrm{J} \mathrm{Med.}$ 1989;321(2):121.

27. Heini PF, Walchli B, Berlemann U. Percutaneous transpedicular vertebroplasty with PMMA: operative technique and early results. A prospective study for the treatment of osteoporotic compression fractures. Eur Spine J. 2000;9(5):445-450. doi:10.1007/s005860000182

28. Shimony JS, Gilula LA, Zeller AJ, Brown DB. Percutaneous vertebroplasty for malignant compression fractures with epidural involvement. Radiology. 2004;232(3):846-853. doi:10.1148/radiol.2323030353

29. Saliou G, Kocheida El M, Lehmann P, et al. Percutaneous vertebroplasty for pain management in malignant fractures of the spine with epidural involvement. Radiology. 2010;254(3):882-890. doi:10.1148/ radiol.09081698

30. Sun G, Jin P, Li M, et al. Percutaneous vertebroplasty for pain management in spinal metastasis with epidural involvement. Technol Cancer Res Treat. 2011;10(3):267-274. doi:10.7785/ tcrt.2012.500202

31. Amoretti N, Diego P, Amelie P, et al. Percutaneous vertebroplasty in tumoral spinal fractures with posterior vertebral wall involvement: feasibility and safety. Eur J Radiol. 2018;104:38-42. doi:10.1016/j. ejrad.2018.04.010

32. Bae JW, Gwak HS, Kim S, et al. Percutaneous vertebroplasty for patients with metastatic compression fractures of the thoracolumbar spine: clinical and radiological factors affecting functional outcomes. Spine J. 2016;16(3):355-364. doi:10.1016/j.spinee.2015.11.033

33. Gangi A, Sabharwal T, Irani FG, Buy X, Morales JP, Adam A. Standards of practice committee of the society of interventional R: quality assurance guidelines for percutaneous vertebroplasty. Cardiovasc Intervent Radiol. 2006;29(2):173-178. doi:10.1007/ s00270-005-0146-5

34. Tomé-Bermejo F, Piñera AR, Duran-Álvarez C, López-San RB, Mahillo I, Alvarez L. Identification of risk factors for the occurrence of cement leakage during percutaneous vertebroplasty for painful osteoporotic or malignant vertebral fracture. Spine J. 2013;13(9): S90-S90. doi:10.1016/j.spinee.2013.07.246

35. Zhu SY, Zhong ZM, Wu Q, Chen JT. Risk factors for bone cement leakage in percutaneous vertebroplasty: a retrospective study of four hundred and eighty five patients. Int Orthop. 2016;40(6):1205-1210. doi:10.1007/s00264-015-3102-2

\section{Dovepress}

\section{Publish your work in this journal}

Therapeutics and Clinical Risk Management is an international, peerreviewed journal of clinical therapeutics and risk management, focusing on concise rapid reporting of clinical studies in all therapeutic areas, outcomes, safety, and programs for the effective, safe, and sustained use of medicines. This journal is indexed on PubMed Central, CAS,
EMBase, Scopus and the Elsevier Bibliographic databases. The manuscript management system is completely online and includes a very quick and fair peer-review system, which is all easy to use. Visit http://www.dovepress.com/testimonials.php to read real quotes from published authors. 